\title{
Association of adiponectin and socioeconomic status in African American men and women: the Jackson heart study
}

Sharon K. Davis ${ }^{1 *}$, Ruihua Xu¹, Pia Riestra', Samson Y. Gebreab', Rumana J. Khan', Amadou Gaye1, DeMarc Hickson ${ }^{2}$, Mario Sims ${ }^{2}$ and Aurelian Bidulescu ${ }^{3}$

\begin{abstract}
Background: Recent emphasis has been placed on elucidating the biologic mechanism linking socioeconomic status (SES) to cardiovascular disease (CVD). Positive associations of inflammatory biomarkers provide evidence suggestive of a biologic pathway by which SES may predispose to CVD. African Americans have disproportionately lower SES and have a higher prevalence of CVD risk factors compared to most ethnic/racial groups. Adiponectin (an anti-inflammatory marker) is also lower. The objective of this study was to assess the association of adiponectin with SES among African American men and women using the Jackson Heart Study.
\end{abstract}

Methods: Study sample included 4340 participants. Linear regression was performed separately by SES and stratified by sex. Annual household income and level of education was used as proxies for SES. Crude, age, health behavior and health status adjusted models were analyzed. The main outcome was log-transformed adiponectin.

Results: Men in the lowest income group had significantly higher adiponectin than those in the highest income group in the fully adjusted model (B/standard error [se], $p$ value $=.16 / .08, p=.0008$. Men with $<$ high school level of education had significantly higher adiponectin in the crude and age adjusted models than those with $\geq$ college degree $(.25 / .05, p<.0001 ; .14 / .05 / p=.005$, respectively). Women with some college or vocational training in the crude and age adjusted models had lower adiponectin compared to women with $\geq$ college degree $(-.09 / .03$, $p=.004 ;-.06 / .03, p=.04$, respectively).

Conclusion: Findings suggest a potential inverse biologic pathway between annual household income and adiponectin among African American men. There was no such finding among women. Findings suggest interventions should be targeted for higher SES African American men to improve adiponectin levels.

Keywords: Biomarkers, Cardiovascular disease, Socioeconomic status, Adiponectin, African Americans

\section{Background}

Research has consistently demonstrated an inverse association with socioeconomic status (SES) and cardiovascular disease (CVD) related mortality, morbidity and risk factors [1-4]. More recent emphasis has been placed on elucidating the biologic mechanism linking SES to CVD [5, 6]. Investigations show a significant inverse association between pro and anti-inflammatory

\footnotetext{
* Correspondence: sharon.davis@nih.gov

${ }^{1}$ Social Epidemiology Research Unit, National Human Genome Research Institute, National Institutes of Health, 10 Center Drive, Room 7 N320, MSC 1644, Bethesda 20892, MD, USA

Full list of author information is available at the end of the article
}

biomarkers with SES which provide evidence suggestive of a biologic pathway by which SES may predispose to CVD [5-10]. These investigations suggest greater inflammation burden in those of lower SES. However, few studies have investigated the socioeconomic patterning of inflammatory biomarkers among African Americans. Those that include African Americans report adverse biomarker concentrations when compared to other racial/ethnic groups [9]. Research also shows lower SES African Americans have a higher prevalence of CVD risk factors [11]. Adiponectin is an anti-inflammatory biomarker that has increasingly been proposed as a risk factor for CVD related outcomes [12]. Adiponectin is a 
type of adipokine that is produced and secreted predominantly by adipocytes and lower levels has deleterious effects on the metabolic and vascular system which is inversely associated with type 2 diabetes and hypertension [13, 14]. Research demonstrates that African Americans have lower levels of adiponectin and a higher prevalence of obesity, hypertension and type 2 diabetes compared to other racial/ethnic groups in the United States [15, 16]. Lower SES is also disproportionately prevalent among African Americans [16]. We are aware of only three studies that compare adiponectin by SES $[10,17,18]$. To date, research has not been conducted in the United States that compares the association between adiponectin and SES among African American men and women or any other racial/ethnic group. Investigating the association between adiponectin and SES may provide important insights into the biological pathways linking SES with CVD and related risk factors in the higher risk population of African Americans. The objective of our study is to test the hypothesis that level of adiponectin may differ by SES among African American men and women and such association may be mediated by health status and health behavior.

\section{Methods}

Data from the Jackson Heart Study (JHS) was used which is a single-site, prospective cohort of risk factors and causes of heart disease in adult African Americans. A probability sample of 5301 African Americans, aged 21-95, residing in three contiguous counties surrounding Jackson, Mississippi was recruited and examined at baseline from 2000 to 2004 by certified technicians according to standardized protocols $[19,20]$. The present study includes cross-sectional data on 4340 participants who had complete data on all variables of interest. Those participants with missing values in the variables of interest were excluded. Baseline examination included blood pressure, anthropometry, survey of medical history, cardiovascular risk factors and collection of blood and urine for biological variables. Written consent was obtained from each participant before the collection of data. The study protocol was approved by the Institutional Review Boards of the National Institutes of Health and the participating JHS institutions-including the University of Mississippi Medical Center, Tougaloo College, and Jackson State University.

\section{Outcome variable}

Adiponectin measurement was derived from venous blood samples drawn from each participant at baseline after more than $8 \mathrm{~h}$ of fasting. Vials of serum were stored at the JHS central repository in Minneapolis, MN, at $-80{ }^{\circ} \mathrm{C}$ until assayed. Adiponectin concentration was measured in 2008-2012 as total plasma adiponectin by an ELISA system (R\&D Systems; Minneapolis, MN. The inter-assay coefficient of variation was $8.8 \%$. No biological degrading has been described using stored specimens, indicating a high validity for measurement [21]. The distribution of plasma adiponectin values were positively skewed and were subsequently log-transformed for statistical analyses.

\section{Primary predictor variable}

We used two measures of SES-self-reported pre-tax annual household income and educational level. Annual household income was divided into three categories $(\leq \$ 19,000, \$ 20,000-\$ 49,000, \geq \$ 50,000)$ and educational level was divided into four categories (<high school, high school or graduate equivalency diploma (GED), some college or vocational school, $\geq$ college graduate).

\section{Covariates}

All covariates were collected at baseline and were chosen because they are associated with adiposity and hypertension related adiponectin [12]. Age was derived from date-of-birth. We further categorize covariates into health behavior and health status as mediator variables to determine if they would affect outcome. Health behavior variables include smoking status, physical activity, alcohol consumption status, and overweight based on body mass index (BMI) [16]. Smoking status was defined as current smokers and non-smokers. Physical activity was assessed with a physical activity survey instrument comprised of 4 domains (active living, work, home and garden, sport and exercise indexes). A total score was the sum of these domains with a maximum of 24 and a higher score indicates a higher level of physical activity. Alcohol consumption status was defined as "yes" if participant reported ever consuming alcohol and "no" for those reporting never consuming alcohol. Overweight was defined as $B M I \geq 25$. Body mass index was derived from standing height and weight measured in lightweight clothing without shoes or constricting garments and calculated as weight in kilograms divided by height in meters squared $\left(\mathrm{kg} / \mathrm{m}^{2}\right)$. Cardiovascular disease health status variables include hypertension, type 2 diabetes, low-density lipoprotein (LDL), high-density lipoprotein (HDL), triglyceride, homoeostasis model assessmentinsulin resistance (HOMA-IR), and C-reactive protein (CRP). Hypertension was based on a systolic blood pressure of $\geq 140 \mathrm{mmHg}$, diastolic blood pressure of $\geq 90 \mathrm{mmHg}$, or self-reported medication use for elevated blood pressure [14]. Blood pressure was measured using standard protocols with participant sitting quietly for $5 \mathrm{~min}$ measured at 1-min intervals. The average of two sitting blood pressure was used in the analysis. Type 2 diabetes was defined as fasting plasma glucose $\geq 126 \mathrm{mg} / \mathrm{dL}$ or selfreported use of insulin or oral hypoglycemic medications 
[13]. Fasting insulin, LDL, HDL and triglyceride were assessed using standard laboratory techniques. Insulin resistance status was estimated with HOMA-IR [22]. CRP was measured using immunoturbidimetric CRP-Latex assay from Kamiya Biomedical Company following manufacturer's high-sensitivity protocol [23]. The inter-assay coefficients of variation on control samples repeated in each assay were 4.5 and $4.4 \%$ at CRP concentrations of 0.45 and $1.56 \mathrm{mg} / \mathrm{dL}$, respectively.

\section{Statistical analyses}

All analyses were sex stratified because of the differential levels of adiponectin between men and women [24]. Descriptive analyses of the characteristics of men and women were performed using two sample $t$-test for continuous variables and chi-square for categorical variables. Characteristics of men and women stratified by annual household income and level of education were performed with oneway ANOVA for continuous variables and chi-square for categorical variables. Differential age adjusted mean levels of adiponectin for men and women by the three categories of income and four categories of education were graphed for descriptive purposes via one-way ANOVA. Adiponectin was based on sample mean.

Multiple linear regression analysis was utilized to test the association separately between two SES groups (i.e. annual household income, educational level) and logtransformed adiponectin with crude, age, health behavior and health status adjusted variables; $\geq \$ 50,000$ and $\geq$ college graduate were entered as referents for annual household income and level of education, respectively. Four separate models per SES group were utilized to test the effects on log-transformed adiponectin in a stepwise fashion. Model 1 was crude and included annual household income and educational level, while model 2 added age entered as a continuous variable. Model 3 added health behavior variables (BMI $\geq 25$, smoking status, alcohol consumption status, physical activity score). Body mass index $\geq 25$, smoking status, and alcohol consumption were entered as binary variables; physical activity was continuous. The fully adjusted model added health status variables (triglycerides, HDL, LDL, HOMA-IR, type 2 diabetes, hypertension and CRP). Triglycerides, HDL, LDL, HOMA-IR and CRP were entered as continuous variables; hypertension and type 2 diabetes were entered as binary variables. Tests of linear trends were also conducted to examine the association of SES sub-groups with levels of log-transformed adiponectin which were exponentiated (i.e. geometric means) after model adjustments based on general linear model. This was done to assess change in the magnitude of difference in adiponectin level between the highest and lowest SES sub-groups and to assess threshold effects between levels after adjustments as a measure of SES disparity and adiponectin level. A two- tailed level of significance was established as $p \leq .05$. Analyses were conducted using SAS version 9.3 [25].

\section{Results}

The sex-stratified characteristics of the study population are presented in Table 1 . Women were significantly older than men (55 years of age versus $54, p=.002$ ). A higher proportion of men had a higher household income of $\geq \$ 50,000$ compared to women (46\% versus $28 \%$, $p<.0001)$. A higher proportion men were current smokers (17.7\% versus $11 \%)$, consumed alcohol (60\% versus $40 \%$ ) and had a higher mean physical activity score (8.7 versus 8.2 ) when compared to women ( $p<.0001$, respectively). Women on the other hand, had significantly higher mean BMI $\left(33 \mathrm{~kg} / \mathrm{m}^{2}\right.$ versus $30 \mathrm{~kg} / \mathrm{m}^{2}$, $p<.0001)$. A higher proportion of women were also hypertensive (64\% versus $60 \%$ ), had type 2 diabetes (19\% versus $16 \%$ ) and had higher mean HDL cholesterol (55 mg/dL versus $46 \mathrm{mg} / \mathrm{dL}$ ), HOMA-IR (3.7 versus 3.4), CRP $(.60 \mathrm{mg} / \mathrm{dL}$ versus $.37 \mathrm{mg} / \mathrm{dL})$, and plasma adiponectin $(6.0 \mathrm{ug} / \mathrm{mL}$ versus $4.1 \mathrm{ug} / \mathrm{mL})$ when compared to men $(p=.009, .003,<.0001,<.0001,<.0001,<.0001$, respectively). Men had higher mean systolic and diastolic blood pressure $(127.9 \mathrm{mmHg}, 81.4 \mathrm{mmHg}$ versus $126.2 \mathrm{mmHg}$, $77.2 \mathrm{mmHg})$, LDL cholesterol (128.7 $\mathrm{mg} / \mathrm{dL}$ versus $125.5 \mathrm{mg} / \mathrm{dL})$, and triglyceride $(114.1 \mathrm{mg} / \mathrm{dL}$ versus $100.3 \mathrm{mg} / \mathrm{dL})(p=.004,<.0001, .006,<.0001$, respectively).

There was a significant differential pattern of mean age and health behavior and health status according to annual income among men and women as revealed in Table 2. Men with an annual income of $\leq \$ 19,000$ were significantly older (57 years) than men in the other income categories $(\mathrm{p}<.0001)$. A higher percentage of men were also current smokers (27\%). Hypertension, systolic blood pressure, HDL cholesterol, and CRP were also significantly higher among this group of men ( $p=<.0002, .0012, .0006, .003$, respectively). On the other hand, physical activity, alcohol consumption, BMI, diastolic blood pressure, and LDL cholesterol was significantly higher among men in the highest annual income category of $\geq \$ 50,000$ when compared to those in the other income groups $(p=<.0001, .0003, .02$, $.0003, .0003, .001$, respectively). Type 2 diabetes, and triglyceride were higher among those with an income of $\$ 20,000-\$ 49,000$ ( $p=<.0001, .03$, respectively). Relatively the same pattern was observed among women. The exception was that those in the lowest income group of $\leq \$ 19,000$ had significantly higher BMI, type 2 diabetes, and triglyceride when compared to women in the other income groups $(p=<.0001,<.0001, .003$, respectively). Educational level with mean age and health behavior and health status patterned similarly among men and women as indicated in Table 3. 
Table 1 Characteristics of study sample $(N=4340)$

\begin{tabular}{|c|c|c|c|}
\hline & \multirow{2}{*}{$\begin{array}{l}\text { Men } \\
(n=1604 \\
36.96 \%)\end{array}$} & \multirow{2}{*}{$\begin{array}{l}\text { Women } \\
(n=2736 \\
63.04 \%)\end{array}$} & \multirow[t]{2}{*}{$P$-value } \\
\hline & & & \\
\hline Age (years), mean \pm std. & $53.86 \pm 13.00$ & $55.06 \pm 12.63$ & .002 \\
\hline \multicolumn{4}{|l|}{ Socioeconomic Indicators } \\
\hline \multicolumn{4}{|l|}{$\begin{array}{l}\text { Annual household } \\
\text { income, } \%\end{array}$} \\
\hline$\leq \$ 19,999$ & 20.95 & 33.77 & - \\
\hline$\$ 20,000-\$ 49,999$ & 33.29 & 38.49 & - \\
\hline$\geq \$ 50,000$ & 45.76 & 27.74 & $<.0001$ \\
\hline \multicolumn{4}{|l|}{ Educational level, \% } \\
\hline$<$ high school & 18.02 & 16.63 & - \\
\hline High school or GED & 18.70 & 19.63 & - \\
\hline Some college or vocational & 29.61 & 29.82 & - \\
\hline$\geq$ College graduate & 33.67 & 33.92 & .65 \\
\hline \multicolumn{4}{|l|}{ Health Behavior } \\
\hline Current smoker, $\%$ & 17.75 & 10.92 & $<.0001$ \\
\hline $\begin{array}{l}\text { Physical activity score, } \\
\text { mean } \pm \text { std. }\end{array}$ & $8.71 \pm 2.61$ & $8.27 \pm 2.57$ & $<.0001$ \\
\hline Alcohol consumption, \% & 60.24 & 39.80 & $<.0001$ \\
\hline $\mathrm{BMI}(\mathrm{kg} / \mathrm{m} 2)$, mean \pm std. & $29.84 \pm 6.22$ & $32.92 \pm 7.63$ & $<.0001$ \\
\hline \multicolumn{4}{|l|}{ Health Status } \\
\hline Hypertension,\% & 59.86 & 63.84 & .009 \\
\hline $\begin{array}{l}\text { Systolic blood pressure } \\
(\mathrm{mmHg}), \text { mean } \pm \text { std. }\end{array}$ & $127.9 \pm 17.82$ & $126.2 \pm 18.42$ & .004 \\
\hline $\begin{array}{l}\text { Diastolic blood pressure } \\
(\mathrm{mmHg}) \text {, mean } \pm \text { std. }\end{array}$ & $81.45 \pm 10.54$ & $77.26 \pm 10.12$ & $<.0001$ \\
\hline Type 2 diabetes, $\%$ & 15.57 & 19.15 & .003 \\
\hline $\begin{array}{l}\text { LDL cholesterol } \\
(\mathrm{mg} / \mathrm{dL}) \text {, mean } \pm \text { std. }\end{array}$ & $128.7 \pm 36.51$ & $125.5 \pm 36.21$ & .006 \\
\hline $\begin{array}{l}\mathrm{HDL} \text { cholesterol } \\
(\mathrm{mg} / \mathrm{dL}) \text {, mean } \pm \text { std. }\end{array}$ & $45.96 \pm 12.45$ & $55.19 \pm 14.61$ & $<.0001$ \\
\hline $\begin{array}{l}\text { Triglyceride level } \\
(\mathrm{mg} / \mathrm{dL}), \text { mean } \pm \mathrm{std} .\end{array}$ & $114.1 \pm 90.22$ & $100.3 \pm 60.35$ & $<.0001$ \\
\hline HOMA-IR, mean \pm std. & $3.43 \pm 2.39$ & $3.78 \pm 2.44$ & $<.0001$ \\
\hline $\begin{array}{l}\text { C-reactive protein } \\
(\mathrm{mg} / \mathrm{dL}), \text { mean } \pm \text { std. }\end{array}$ & $.37 \pm 1.04$ & $.60 \pm 0.84$ & $<.0001$ \\
\hline $\begin{array}{l}\text { Plasma adiponectin } \\
(\mathrm{ug} / \mathrm{mL}), \text { mean } \pm \text { std. }\end{array}$ & $4.15 \pm 3.36$ & $6.09 \pm 4.56$ & $<.0001$ \\
\hline
\end{tabular}

Abbreviations: std standard deviation, GED graduate equivalency diploma, BMI body mass index, $L D L$ low-density lipoprotein, $H D L$ high-density lipoprotein, HOMA-IR homoeostasis model assessment-insulin resistance

Figure 1 illustrates mean age adjusted adiponectin was significantly different among men by annual household income with those in the lowest category having higher adiponectin $(p<.0001)$. There was no difference among women. Mean adiponectin was also significantly different among men and women based on level of education with those with $<$ high school level of education having higher adiponectin $(p<.0001, .007$, respectively).

Table 4 reveals men with a lower annual income of $\leq$ $\$ 19,999$ had significantly higher plasma adiponectin when compared to men with a higher income of $\geq$ $\$ 50,000$. This was evident in the crude model ( $\beta$ (se) $=.26(.04) ; p<.0001)$ and persisted in the fully adjusted model $(\beta(\mathrm{se})=.16(.05) ; p=.0008)$. The reduction in model coefficients ranged from 19 to $38 \%$. Those with a medium annual income of $\$ 20,000-\$ 49,000$ had marginally higher plasma adiponectin than men with a higher annual income of $\geq \$ 50,000$. Men with $<$ high school level of education had significantly higher adiponectin in the crude model $(\beta(\mathrm{se}) .25(.05) ; p<.0001)$ and remained significant when adjusted for age $(\beta$ (se) .14 (.05); $p$ $=.005$ ), but significance disappeared after adjustment for health behavior and health status; the coefficients between both models were reduced by $44 \%$. There was no association among men with high school or GED level of education or among those with some college or vocational training.

There was no significant association between annual household income and plasma adiponectin observed among women in any of the models. In the crude model, women with some college or vocational training had significantly lower levels of adiponectin than women with $\geq$ college level of education ( $\beta$ (se) .09 (03), $p=.004$ ). When adjusted for age, women with $<$ high school level of education and those with some college or vocational training had significantly lower plasma adiponectin than women with $\geq$ college level ( $\beta$ (se)-.08 (.04), $p=.03,-.06$ (.03), $p=.04$, respectively). A $33 \%$ reduction in coefficients between crude and age adjusted models was observed among those with some college or vocational training. There was no association in the models adjusted for health behavior or health status.

Table 5 presents the trends of log-transformed exponentiated level of adiponectin for income and level of education for each sub-group compared with the highest sub-group. The results show that men with an annual household income of $\leq \$ 19,999$ and $\$ 20,000-\$ 49,000$ had significantly higher mean adiponectin than those with an income of $\geq \$ 50,000$ (3.91 and 3.25 versus 3.02 , $p<.0001)$ in the crude unadjusted model. This pattern persisted in each of the subsequently adjusted models. There were no differences observed among women by level of income in the crude, age, health behavior, and health status adjusted models. In the crude model, men who had an education level of $<$ high school and those with high school or GED, had higher levels of mean adiponectin than men with $\geq$ college level of education $(3.98,3.26$ versus $3.10, p<.0001)$. A similar pattern was observed in the age-adjusted 
Table 2 Characteristics among men and women stratified by annual household income $(N=4340)$

\begin{tabular}{|c|c|c|c|c|}
\hline & \multicolumn{4}{|c|}{ Annual household income } \\
\hline & $\leq \$ 19,999$ & $\$ 20,000-\$ 49,999$ & $\geq \$ 50,000$ & $P$-value \\
\hline \multicolumn{5}{|l|}{ Men $(n=1604)$} \\
\hline Age (years), mean \pm std & $57.56 \pm 15.25$ & $54.25 \pm 13.09$ & $51.87 \pm 11.33$ & $<.0001$ \\
\hline \multicolumn{5}{|l|}{ Health Behavior } \\
\hline Current smoker, \% & 27.16 & 18.64 & 12.77 & $<.0001$ \\
\hline Physical activity score, mean \pm std & $7.51 \pm 2.77$ & $8.64 \pm 2.54$ & $9.30 \pm 2.39$ & $<.0001$ \\
\hline Alcohol consumption, $\%$ & 52.99 & 57.97 & 65.21 & .0003 \\
\hline $\mathrm{BMI}\left(\mathrm{kg} / \mathrm{m}^{2}\right)$, mean $\pm \mathrm{std}$ & $29.05 \pm 6.97$ & $29.93 \pm 6.33$ & $30.13 \pm 5.75$ & .02 \\
\hline \multicolumn{5}{|l|}{ Health Status } \\
\hline Hypertension, \% & 67.37 & 62.36 & 54.61 & .0002 \\
\hline $\mathrm{SBP}(\mathrm{mmHg})$, mean \pm std & $129.87 \pm 20.61$ & $129.00 \pm 17.72$ & $126.13 \pm 16.32$ & .0012 \\
\hline $\mathrm{DBP}(\mathrm{mmHg})$, mean \pm std & $79.42 \pm 10.88$ & $81.68 \pm 10.89$ & $82.20 \pm 10.02$ & .0003 \\
\hline Type 2 diabetes, \% & 18.90 & 20.95 & 10.12 & $<.0001$ \\
\hline LDL cholesterol $(\mathrm{mg} / \mathrm{dL})$, mean \pm std & $122.67 \pm 37.74$ & $128.51 \pm 38.93$ & $131.59 \pm 33.83$ & .001 \\
\hline $\mathrm{HDL}$ cholesterol $(\mathrm{mg} / \mathrm{dL})$, mean \pm std & $48.32 \pm 14.46$ & $45.79 \pm 12.27$ & $45.05 \pm 11.48$ & .0006 \\
\hline Triglyceride $(\mathrm{mg} / \mathrm{dl})$, mean \pm std & $107.90 \pm 68.29$ & $117.06 \pm 75.47$ & $114.69 \pm 106.62$ & .03 \\
\hline HOMA-IR, mean \pm std & $3.16 \pm 2.03$ & $3.53 \pm 3.02$ & $3.49 \pm 2.03$ & .10 \\
\hline $\mathrm{CRP}(\mathrm{mg} / \mathrm{dL})$, mean $\pm \mathrm{std}$ & $0.52 \pm 1.95$ & $0.39 \pm 0.67$ & $0.29 \pm 0.52$ & .003 \\
\hline \multicolumn{5}{|l|}{ Women $(n=2736)$} \\
\hline Age (years), mean \pm std & $58.67 \pm 14.01$ & $54.25 \pm 11.91$ & $51.80 \pm 10.61$ & $<.0001$ \\
\hline \multicolumn{5}{|l|}{ Health Behavior } \\
\hline Current smoker, \% & 15.25 & 10.21 & 6.62 & $<.0001$ \\
\hline Physical activity score, mean \pm std & $7.59 \pm 2.69$ & $8.31 \pm 2.51$ & $9.04 \pm 2.25$ & $<.0001$ \\
\hline Alcohol consumption, $\%$ & 31.33 & 37.12 & 53.76 & $<.0001$ \\
\hline $\mathrm{BMI}\left(\mathrm{kg} / \mathrm{m}^{2}\right)$, mean $\pm \mathrm{std}$ & $33.49 \pm 8.30$ & $33.13 \pm 7.58$ & $31.92 \pm 6.71$ & $<.0001$ \\
\hline \multicolumn{5}{|l|}{ Health Status } \\
\hline Hypertension, \% & 72.19 & 64.11 & 53.26 & $<.0001$ \\
\hline $\mathrm{SBP}(\mathrm{mmHg})$, mean \pm std & $129.88 \pm 20.03$ & $125.78 \pm 17.82$ & $122.46 \pm 16.26$ & $<.0001$ \\
\hline $\mathrm{DBP}(\mathrm{mmHg})$ & $76.83 \pm 10.72$ & $77.69 \pm 10.08$ & $77.19 \pm 9.39$ & .16 \\
\hline Type 2 diabetes, $\%$ & 25.88 & 17.37 & 13.47 & $<.0001$ \\
\hline LDL cholesterol $(\mathrm{mg} / \mathrm{dL})$, mean \pm std & $126.47 \pm 37.80$ & $126.03 \pm 35.89$ & $123.69 \pm 34.72$ & .26 \\
\hline $\mathrm{HDL}$ cholesterol $(\mathrm{mg} / \mathrm{dL})$, mean \pm std & $55.19 \pm 15.19$ & $55.32 \pm 14.62$ & $55.00 \pm 13.93$ & .90 \\
\hline Triglyceride $(\mathrm{mg} / \mathrm{dl})$, mean \pm std & $105.42 \pm 65.37$ & $99.85 \pm 58.84$ & $95.12 \pm 55.81$ & .003 \\
\hline HOMA-IR, mean \pm std & $3.87 \pm 2.28$ & $3.84 \pm 2.60$ & $3.63 \pm 2.40$ & .14 \\
\hline $\mathrm{CRP}(\mathrm{mg} / \mathrm{dL})$, mean $\pm \mathrm{std}$ & $0.64 \pm 0.95$ & $0.60 \pm 0.79$ & $0.53 \pm 0.75$ & .02 \\
\hline
\end{tabular}

Abbreviations: std standard deviation, $B M I$ body mass index, SBP systolic blood pressure, DBP diastolic blood pressure, $L D L$ low-density lipoprotein, $H D L$ high-density lipoprotein, HOMA-IR homoeostasis model assessment-insulin resistance, CRP C-reactive protein

model $(p=.006)$. But differences by education level were attenuated in the models adjusted for health behavior and health status. Women with an education of $<$ high school, high school or GED, and those with some college or vocational training had lower levels of adiponectin than women with $\geq$ college level of education $(4.74,4.88,4.84$ versus $5.15 ; p \leq .05)$ after adjustment for age. This significance, however, disappeared in the fully adjusted model.

\section{Discussion}

Consistent observations of SES gradients in health outcomes has led to the search for pathways through which social status may impact health-including biological mechanisms through which social characteristics and 
Table 3 Characteristics among men and women stratified by education ( $N=4340)$

\begin{tabular}{|c|c|c|c|c|c|}
\hline & \multicolumn{5}{|l|}{ Education } \\
\hline & $<$ high school & High school or GED & Some college or vocational & $\geq$ College graduate & $P$-value \\
\hline \multicolumn{6}{|l|}{ Men $(n=1604)$} \\
\hline Age (years), mean \pm std & $65.05 \pm 10.64$ & $53.34 \pm 12.73$ & $48.92 \pm 11.93$ & $52.49 \pm 11.67$ & $<.0001$ \\
\hline \multicolumn{6}{|l|}{ Health Behavior } \\
\hline Current smoker, $\%$ & 22.22 & 20.40 & 21.70 & 10.43 & $<.0001$ \\
\hline Physical activity score, mean \pm std & $6.99 \pm 2.46$ & $8.38 \pm 2.59$ & $9.41 \pm 2.52$ & $9.18 \pm 2.34$ & $<.0001$ \\
\hline Alcohol consumption, \% & 46.15 & 58.67 & 64.48 & 64.87 & $<.0001$ \\
\hline $\mathrm{BMI}\left(\mathrm{kg} / \mathrm{m}^{2}\right)$, mean $\pm \mathrm{std}$ & $28.57 \pm 5.70$ & $29.34 \pm 5.58$ & $30.60 \pm 6.77$ & $30.11 \pm 6.21$ & $<.0001$ \\
\hline \multicolumn{6}{|l|}{ Health Status } \\
\hline Hypertension, \% & 76.22 & 60.54 & 53.32 & 56.45 & $<.0001$ \\
\hline $\mathrm{SBP}(\mathrm{mmHg})$, mean \pm std & $132.87 \pm 20.89$ & $128.47 \pm 17.47$ & $126.20 \pm 16.96$ & $126.26 \pm 16.78$ & $<.0001$ \\
\hline $\mathrm{DBP}(\mathrm{mmHg})$, mean \pm std & $79.10 \pm 10.76$ & $81.50 \pm 10.37$ & $82.57 \pm 11.01$ & $81.69 \pm 9.93$ & 0.0002 \\
\hline Type 2 diabetes, \% & 24.03 & 16.89 & 13.33 & 12.26 & $<.0001$ \\
\hline LDL cholesterol $(\mathrm{mg} / \mathrm{dL})$, mean \pm std & $126.54 \pm 38.75$ & $126.98 \pm 36.27$ & $129.01 \pm 35.87$ & $130.56 \pm 36.05$ & 0.4188 \\
\hline $\mathrm{HDL}$ cholesterol $(\mathrm{mg} / \mathrm{dL})$, mean \pm std & $48.34 \pm 13.90$ & $46.04 \pm 11.86$ & $45.51 \pm 12.43$ & $45.13 \pm 11.91$ & 0.0068 \\
\hline Triglyceride $(\mathrm{mg} / \mathrm{dl})$, mean \pm std & $109.24 \pm 68.53$ & $108.55 \pm 62.68$ & $123.60 \pm 95.59$ & $111.13 \pm 105.56$ & 0.0643 \\
\hline HOMA-IR, mean \pm std & $3.15 \pm 1.89$ & $3.42 \pm 2.27$ & $3.52 \pm 2.00$ & $3.51 \pm 2.89$ & 0.2609 \\
\hline $\mathrm{CRP}(\mathrm{mg} / \mathrm{dL})$, mean $\pm \mathrm{std}$ & $0.59 \pm 2.11$ & $0.36 \pm 0.62$ & $0.32 \pm 0.49$ & $0.31 \pm 0.60$ & 0.0013 \\
\hline \multicolumn{6}{|l|}{ Women $(n=2736)$} \\
\hline Age (years), mean \pm std & $64.97 \pm 10.11$ & $57.11 \pm 12.26$ & $50.32 \pm 11.97$ & $53.20 \pm 11.56$ & $<.0001$ \\
\hline \multicolumn{6}{|l|}{ Health Behavior } \\
\hline Current smoker, \% & 13.00 & 11.63 & 12.95 & 7.69 & 0.0014 \\
\hline Physical activity score, mean \pm std & $6.69 \pm 2.42$ & $7.83 \pm 2.60$ & $8.71 \pm 2.48$ & $8.89 \pm 2.33$ & $<.0001$ \\
\hline Alcohol consumption, \% & 20.13 & 33.90 & 44.35 & 48.86 & $<.0001$ \\
\hline $\mathrm{BMI}\left(\mathrm{kg} / \mathrm{m}^{2}\right)$, mean $\pm \mathrm{std}$ & $33.42 \pm 7.75$ & $33.06 \pm 7.44$ & $33.66 \pm 8.21$ & $31.93 \pm 7.04$ & $<.0001$ \\
\hline \multicolumn{6}{|l|}{ Health Status } \\
\hline Hypertension, \% & 82.52 & 69.81 & 57.76 & 56.55 & $<.0001$ \\
\hline $\mathrm{SBP}(\mathrm{mmHg})$, mean \pm std & $132.34 \pm 19.42$ & $128.55 \pm 20.03$ & $124.12 \pm 17.44$ & $123.80 \pm 16.92$ & $<.0001$ \\
\hline $\mathrm{DBP}(\mathrm{mmHg})$, mean $\pm \mathrm{std}$ & $75.21 \pm 10.05$ & $77.89 \pm 10.27$ & $78.00 \pm 10.15$ & $77.24 \pm 9.92$ & $<.0001$ \\
\hline Type 2 diabetes, \% & 31.01 & 18.49 & 16.89 & 15.75 & $<.0001$ \\
\hline LDL cholesterol $(\mathrm{mg} / \mathrm{dL})$, mean \pm std & $128.75 \pm 37.36$ & $127.76 \pm 36.95$ & $125.11 \pm 37.74$ & $123.06 \pm 33.63$ & 0.0259 \\
\hline $\mathrm{HDL}$ cholesterol $(\mathrm{mg} / \mathrm{dL})$, mean \pm std & $56.38 \pm 16.02$ & $55.70 \pm 14.86$ & $53.59 \pm 13.28$ & $55.74 \pm 14.81$ & 0.0084 \\
\hline Triglyceride $(\mathrm{mg} / \mathrm{dl})$, mean \pm std & $105.28 \pm 54.41$ & $98.73 \pm 48.31$ & $103.63 \pm 67.07$ & $96.02 \pm 62.63$ & 0.0196 \\
\hline HOMA-IR, mean \pm std & $4.08 \pm 2.56$ & $3.89 \pm 2.50$ & $3.84 \pm 2.30$ & $3.57 \pm 2.48$ & 0.0104 \\
\hline $\mathrm{CRP}(\mathrm{mg} / \mathrm{dL})$, mean $\pm \mathrm{std}$ & $0.67 \pm 1.04$ & $0.58 \pm 0.79$ & $0.64 \pm 0.85$ & $0.53 \pm 0.74$ & 0.0104 \\
\hline
\end{tabular}

Abbreviations: std standard deviation, $B M I$ body mass index, $S B P$ systolic blood pressure, $D B P$ diastolic blood pressure, $L D L$ low-density lipoprotein, $H D L$ high-density lipoprotein, HOMA-IR homoeostasis model assessment-insulin resistance, CRP C-reactive protein

experiences may affect functioning and disease outcomes. One biological pathway that is gaining increasing interest is subclinical inflammatory processes that are thought to be involved in both the development and progression of a number of diseases, including cardiovascular, for which there are known SES gradients [5-10]. Adiponectin is an anti-inflammatory biomarker linked to CVD [12]. A low concentration of circulating adiponectin has been associated with a higher risk of CVD and its related risk factors, including hypertension, type 2 diabetes and obesity $[12,13,26]$. In addition, these outcomes are strongly patterned by SES [4]. African Americans have lower levels of adiponectin, higher prevalence of hypertension, type 2 diabetes, obesity, and lower SES is disproportionately prevalent in this population when compared to other racial/ethnic groups $[15,16]$. The purpose of our 

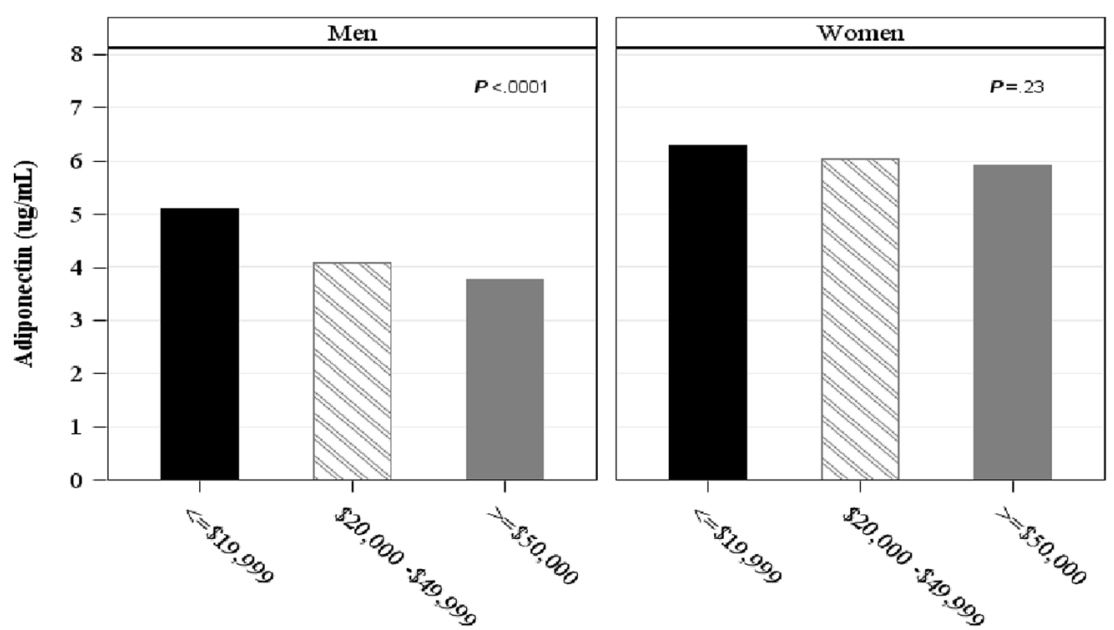

Annual Household Income

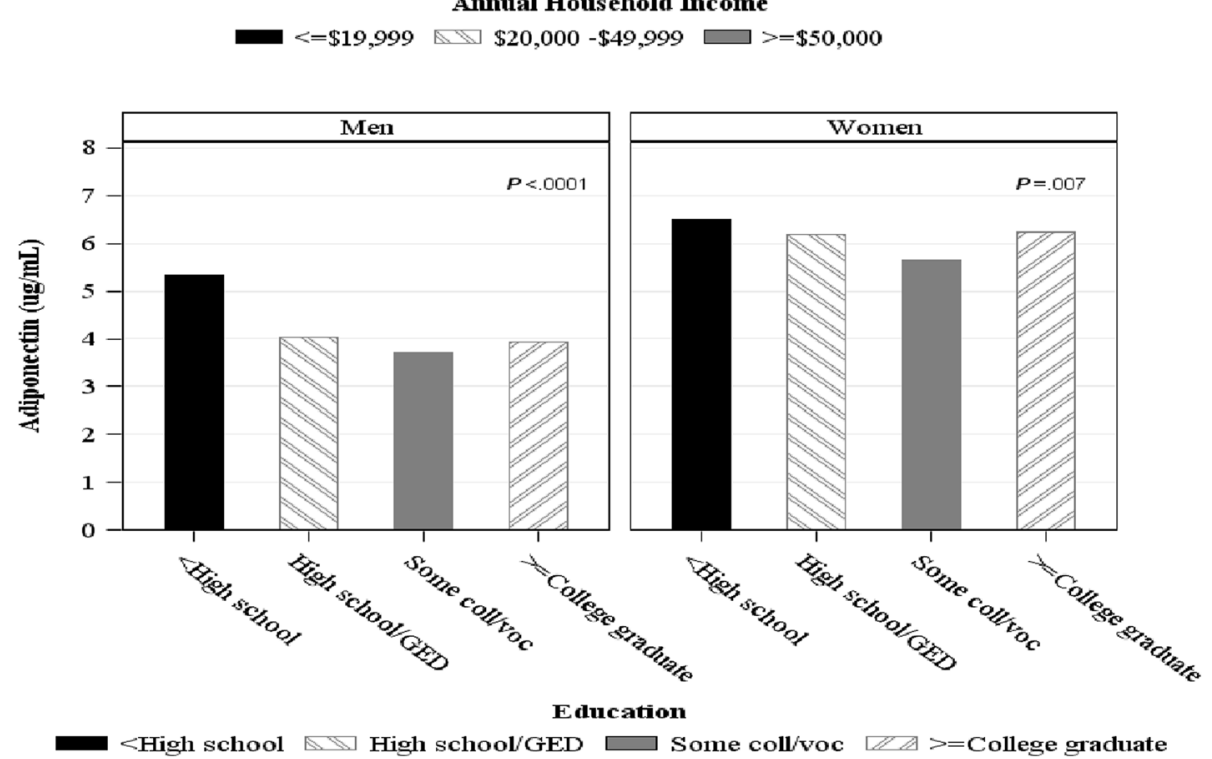

Fig. 1 Mean age adjusted level of adiponectin for men and women by annual household income and level of education. $P$ value represents differences in the level of adiponectin for income and education categories based on one-way ANOVA

study was to investigate the relationship of SES, based on annual household income and level of education, on level of adiponectin among African American men and women. Unlike the association between SES and other novel biomarkers [5-10], our findings revealed lower SES African American men had higher protective levels of adiponectin when compared to higher SES men. For example, African American men with the lowest household income had higher levels of adiponectin than those with the highest household income. Adjusting for health behavior and health status attenuated the association, but remained a strong statistical significance. The relationship regarding adiponectin and level of education was only significant in the crude and age adjusted models resulting in a mediating effect with health behavior and health status. There was no association between annual household income and differential levels of adiponectin among women. However, consistent with other studies assessing SES and biomarkers [5-9], women in our study with lower levels of education also had lower adiponectin levels compared to women with $\geq$ college level of education. However, this relationship disappeared after adjustments for health behavior and health status.

To our knowledge, there are only three publications that investigated the relationship between SES and adiponectin. Khanolkar, Vagero and Koupil investigated the association of occupational class and educational level among a sample of Swedish men 50 to 70 years of age [10]. They found no association between these SES measures and adiponectin levels. Researchers in South Africa investigated the association of adipokine levels and educational level between African and Asian-Indian women 
Table 4 Regression coefficients with standard error of log transformed adiponectin by socioeconomic status for men and women $(N=4340)$

\begin{tabular}{|c|c|c|c|c|c|c|c|c|c|c|c|}
\hline \multicolumn{12}{|l|}{ Adiponectin } \\
\hline \multicolumn{12}{|l|}{ Men $(n=1604)$} \\
\hline & ${ }^{\mathrm{a}}$ Model 1 & & ${ }^{\mathrm{b}}$ Model 2 & & & ${ }^{c}$ Model 3 & & & ${ }^{\mathrm{d}}$ Model 4 & & \\
\hline Socioeconomic status & $\beta(\mathrm{se})$ & $P$-value & $\beta(\mathrm{se})$ & $P$-value & $\%$ Red & $\beta(\mathrm{se})$ & $P$-value & $\%$ Red & $\beta(\mathrm{se})$ & $P$-value & $\%$ Red \\
\hline \multicolumn{12}{|l|}{ Income } \\
\hline$\leq \$ 19,999$ & $.26(.04)$ & $<.0001$ & $.21(.04)$ & $<.0001$ & $19 \%$ & $.15(.05)$ & .0012 & $42 \%$ & $.16(.05)$ & .0008 & $38 \%$ \\
\hline$\$ 20,000-\$ 49,999$ & $.07(0.04)$ & .056 & $.05(.04)$ & .17 & & $.03(.04)$ & .43 & & $.04(.04)$ & .25 & \\
\hline$\geq \$ 50,000$ (referent) & - & & & & & & & & & & \\
\hline \multicolumn{12}{|l|}{ Education } \\
\hline$<$ high school & $.25(.05)$ & $<.0001$ & $.14(.05)$ & .005 & $44 \%$ & $.10(.05)$ & .06 & & $.08(.06)$ & .16 & \\
\hline High school or GED & $.05(.05)$ & .29 & $.04(.05)$ & .36 & & $.01(.05)$ & .87 & & $.03(.05)$ & .55 & \\
\hline Some college or vocational & $-.009(.04)$ & .83 & $.02(.04)$ & .60 & & $.01(.04)$ & .73 & & $.001(004)$ & .96 & \\
\hline$\geq$ College graduate (referent) & - & & & & & & & & & & \\
\hline \multicolumn{12}{|l|}{ Women $(n=2736)$} \\
\hline \multicolumn{12}{|l|}{ Income } \\
\hline$\leq \$ 19,999$ & $.02(.03)$ & .53 & $-.04(.03)$ & .20 & & $-.03(.03)$ & .38 & & $-.01(.03)$ & .73 & \\
\hline$\$ 20,000-\$ 49,999$ & $0.01(0.03)$ & .71 & $-.01(.03)$ & .73 & & $.008(.03)$ & .79 & & $-.0002(.03)$ & .99 & \\
\hline$\geq \$ 50,000$ (referent) & - & & & & & & & & & & \\
\hline \multicolumn{12}{|l|}{ Education } \\
\hline$<$ high school & $.02(.04)$ & .52 & $-.08(.04)$ & .03 & & $-.05(.04)$ & .19 & & $-005(.04)$ & .19 & \\
\hline High school or GED & $-.02(.03)$ & .60 & $-.05(.03)$ & .12 & & $-.03(.04)$ & .44 & & $-.03(.03)$ & .35 & \\
\hline Some college or vocational & $-.09(.03)$ & .004 & $-.06(.03)$ & .04 & $33 \%$ & $-.03(.03)$ & .31 & & $.01(.03)$ & 0.75 & \\
\hline 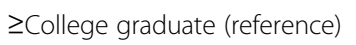 & - & & & & & & & & & & \\
\hline
\end{tabular}

Abbreviations: SE standard error, Red Reduction

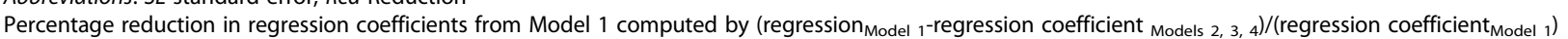
${ }^{\text {a }}$ Model 1, unadjusted

${ }^{\mathrm{b}}$ Model 2, adjusted for age

${ }^{c}$ Model 3, adjusted for age and health behavior (overweight, smoking status, alcohol consumption status, physical activity)

${ }^{\mathrm{d}}$ Model 4, adjusted for age, health behavior and health status (HDL, LDL, triglycerides, hypertension status, type 2 diabetes status, HOMA-IR, CRP)

[18]. They also report no differential association between educational level and this adipokine. Buchan et al. report on the relationship of SES and adiponectin among a sample of adolescent boys and girls in Scotland [17]. Their findings revealed boys and girls from a lower SES had significantly lower adiponectin than those from a higher SES. This finding is consistent with our observation concerning women. Our findings concerning men, on the other hand, is contrary with the findings of Buchan et al. and other investigators assessing the relationship between SES and other novel biomarkers [5-10, 27]. These investigations revealed deleterious biomarker levels among the lower SES group. This was particularly evident regarding the association of annual household income. Our findings concerning the association of income and level of education among men may be due to how SES indices differentially affect health through inflammatory and anti-inflammatory biomarkers. Several studies have found that income and education are independently associated with health $[28,29]$, only one study has examined their shared or independent associations with a biomarker [30]. Results showed lower education predicted higher CRP levels independent of income in a sample of patients with heart disease [31]. However, racial differences were not reported. In African Americans, it may be that social position based on income among men affects health differently than educational status. Proximate factors associated with income may indeed be a stronger predictor of adiponectin than more distal factors related to education. Indeed, men in the lowest income category in our study had significantly higher protective levels of adiponectin than men in the highest income category after adjustments for health behavior and health status; BMI was also lower in this group but higher among men in the highest income category (Table 2). These findings suggest that higher income men may have an economic advantage 
Table 5 Geometric mean difference in adiponectin level for each socioeconomic status category compared to highest category based on general linear model

\begin{tabular}{|c|c|c|c|c|c|c|c|c|}
\hline \multirow[t]{2}{*}{ Adiponectin } & \multicolumn{4}{|l|}{ Men } & \multicolumn{4}{|l|}{ Women } \\
\hline & Model: & & & & Model: & & & \\
\hline Income & $\mathrm{a}_{1}$ & $b_{2}$ & $c_{3}$ & $d_{4}$ & ${ }^{a} 1$ & $b_{2}$ & $c_{3}$ & ${ }^{d} 4$ \\
\hline$\leq \$ 19,999$ & 3.91 & 3.78 & 4.17 & 3.88 & 4.98 & 5.33 & 5.33 & 5.11 \\
\hline$\$ 20,000-\$ 49,999$ & 3.25 & 3.24 & 3.70 & 3.46 & 4.94 & 5.53 & 5.53 & 5.17 \\
\hline$\geq \$ 50,000$ (referent) & 3.02 & 3.07 & 3.59 & 3.31 & 4.88 & 5.48 & 5.48 & 5.17 \\
\hline$P$ for linear trend & $<.0001$ & $<.0001$ & .001 & .0008 & .53 & .20 & .38 & .7370 \\
\hline Education & $a_{1}$ & $b_{2}$ & $c_{3}$ & ${ }^{d} 4$ & $a_{1}$ & $b_{2}$ & $c_{3}$ & $\mathrm{~d}_{4}$ \\
\hline$<$ high school & 3.98 & 3.62 & 4.07 & 3.71 & 5.18 & 4.74 & 5.28 & 4.94 \\
\hline High school or GED & 3.26 & 3.28 & 3.71 & 3.53 & 4.97 & 4.88 & 5.42 & 5.04 \\
\hline Some college or vocational & 3.07 & 3.21 & 3.73 & 3.44 & 4.64 & 4.84 & 5.39 & 5.26 \\
\hline$\geq$ College graduate (referent) & 3.10 & 3.14 & 3.68 & 3.43 & 5.06 & 5.15 & 5.57 & 5.21 \\
\hline$P$ for linear trend & $<.0001$ & .006 & .08 & .14 & .22 & .05 & .23 & .12 \\
\hline
\end{tabular}

Abbreviations: GED graduate equivalency diploma

${ }^{a}$ Model 1, unadjusted

${ }^{\mathrm{b}}$ Model 2, adjusted for age

'Model 3, adjusted for age and health behavior (overweight, smoking status, alcohol consumption status, physical activity)

${ }^{\mathrm{d}}$ Model 4, adjusted for age, health behavior and health status (HDL, LDL, triglycerides, hypertension status, type 2 diabetes status, HOMA-IR, CRP)

and very little barriers to access and exposure to high fat diet unlike potential economic barriers experienced by men in the lowest income category.

\section{Strengthens and limitations}

The strength of our investigation is that findings were from the largest community-based sample of African Americans, a cohort with strict protocol and high qualitycontrol. It also addresses a risk factor (i.e. adiponectin) associated with CVD that disproportionately affects African Americans. In addition, it presents contrary new insight into historical findings concerning SES gradients and health-particularly among men. Finally, it is among the first to report on the association between SES and adiponectin based on a sample population in the United States. One limitation of the study is that findings cannot be generalizable to other ethnic groups. Secondly, this is a cross-sectional analysis; thus, we cannot establish a causal relationship between SES and adiponectin. Furthermore, residual confounders may have impacted the results. It is also important to mention that we use level of education and annual household income as proxy measures of SES and not a composite measure of SES. Although we adjusted for several known confounders, our study did not adjust for other factors such as dietary intake, sex hormones, and specific adiposity measures such as visceral fat. Finally, our study used total adiponectin rather than high molecular weight (HMW) adiponectin, which is considered the most biologically active form. This could potentially affect our findings since some studies suggest differences in biological activity between different isoforms of adiponectin and metabolic abnormalities [22]. However, findings also demonstrate that HMW does not provide more significant information than total adiponectin [32].

\section{Conclusion}

The major finding of our study revealed that, after adjustments for age, health behavior and health status, adiponectin was significantly higher in African American men in the lowest category of income compared to those in the highest income category. Adiponectin was also higher among men with the lowest level of education after adjustment for age. Women with $<$ high school and some college or vocational level of education had lower adiponectin than women with the highest level of education after age adjustment. Findings suggest a potential inverse biological pathway associated with annual household income as a measure of SES and adiponectin in men. Findings further suggest that perhaps intervention should be targeted to higher SES African American men to improve adiponectin level.

\section{Abbreviations}

BMI, body mass index; CRP, C-reactive protein; CVD, cardiovascular disease; GED, graduate equivalency diploma; HDL, high-density lipoprotein; HOMA-IR, homoeostasis model assessment - insulin resistance; JHS, Jackson Heart Study; LDL, low-density lipoprotein; SES, socioeconomic status

\section{Acknowledgements}

The authors would like to thank the staff and the participants of the Jackson Heart Study for their valuable contributions.

Funding for the Jackson Heart Study was supported by contracts HHSN268201200046C, HHSN26820120047C, HHSM268201300048C, HHSN26820130049C, HHSN268201300050C from the National Heart, Lung and Blood Institute and the National Institute on Minority Health and Health 
Disparities. The adiponectin measurements were partially supported by PHS Award UL1RR025008 from the National Center for Research Resources and by grant UH1HL073461 from the National Heart, Lung and Blood Institute. Sharon K. Davis, Ruihua Xu, Pia Riestra, Samson Y. Gebreab, Rumana J. Khan and Amadou Gaye are supported by the intramural program of the National Human Genome Research Institute, National Institutes of Health. The National Human Genome Research Institute supported the design and conduct of the study, management of analyses, interpretation of the data, review and approval of the manuscript. Sharon K. Davis had full access to all the data in the study and takes responsibility for the integrity of the data and the accuracy of the data analysis. The authors have no disclosures to report.

\section{Availability of data and materials}

Data associated with this study will not be made available. All data associated with Jackson Heart Study requires prior approval of a manuscript proposal by Presentation and Publications and Sub-Committee and is therefore not the domain of the authors but that of the Jackson Heart Study, consequently the data will not be shared.

\section{Authors' contributions}

SKD designed the study, analyzed and interpreted the data, discussed the results, wrote, edited and drafted the paper. SYG analyzed and interpreted the data, edited and assisted with drafting the paper. RX carried out statistical analyses for the study, edited and assisted with drafting the paper. PR analyzed the data, discussed the results, edited and assisted with drafting the paper. RJK analyzed the data, edited and assisted with drafting the paper. AG analyzed the data, discussed the results, edited and assisted with drafting the paper. DH, MS analyzed the data, edited and assisted with drafting the paper. $A B$ acquired the adiponectin data, analyzed, edited and assisted with drafting the paper. SKD is the guarantor of this work and, as such, had full access to all the data in the study and takes responsibility for the integrity of the data and the accuracy of the data. All authors have read and approved the final version of the manuscript.

\section{Competing interests}

None of the authors have any financial or non-financial conflicts of interest to report.

\section{Consent for publication}

Not applicable.

\section{Ethics approval and consent to participate}

Ethics approval and written consent was obtained from each participant before the collection of data. The study protocol was approved by the Institutional Review Boards of the National Institutes of Health and the participating JHS institutions-including the University of Mississippi Medical Center, Tougaloo College, and Jackson State University.

\section{Author details}

${ }^{1}$ Social Epidemiology Research Unit, National Human Genome Research Institute, National Institutes of Health, 10 Center Drive, Room 7 N320, MSC 1644, Bethesda 20892, MD, USA. ²University of Mississippi Medical Center, Jackson, USA. ${ }^{3}$ University of Indiana, School of Public Health, Bloomington, USA.

Received: 12 January 2016 Accepted: 26 May 2016

\section{Published online: 14 June 2016}

\section{References}

1. Grotto I, Huerta M, Sharabi V. Hypertension and socioeconomic status. Curr Opin Cardiol. 2008;23:335-9.

2. Rawshani A, Svensson AM, Rosengren A, Eliasson B, Gudbjornsdottir S. Impact of socioeconomic status on cardiovascular disease and mortality in 24,947 individuals with type 1 diabetes. Diabetes Care. doi:10.2337/dc15-0145.

3. Lee RJ, Paultre F, Mosca L. The association between educational level and risk of cardiovascular disease fatality among women with cardiovascular disease. Wom Health Iss. 2005;15:80-8.

4. Shea S, Stein AD, Basch CE, Lantigua R, Maylahn C, Strogatz DS, Novick L. Independent associations of education attainment and ethnicity with behavioral risk factors for cardiovascular disease. Am Jou Epi. 1991;134:567-82.
5. Jousilahti P, Salomaa V, Rasi V, Bahtera E, Palosuo T. Association of markers of systemic inflammation, C-reactive protein, serum amyloid a, and fibrinogen with socioeconomic status. J Epidemiol Community Health. 2003;57:730-3.

6. Loucks EB, Sullivan LM, Hayes LJ, D'Agostino RR, Larson MG, Vasan RS, Benjamin EJ, Berkman LF. Association of educational level with inflammatory markers in the Framingham offspring study. Am J Epidemiol. 2006;163:622-8.

7. Markowe HL, Marmot MG, Shipley MJ, Bulpitt CJ, Meade TW, Stirling Y, Vickers MV, Semmence A. Fibrinogen: a possible link between social class and coronary heart disease. Br Med J (Clin Res Ed). 1985;291:1312-4.

8. Muennig P, Sohler N, Mahato B. Socioeconomic status as an independent predictor of physiological biomarkers of cardiovascular disease: evidence from NHANES. Prev Med. 2007;45:35-40.

9. Gruenewald TL, Cohen S, Matthews KA, Tracy R, Seeman TE. Association of socioeconomic status with inflammation markers in black and white men and women in the coronary artery risk development in young adults (CARDIA) study. Soc Sci Med. 2009;69:451-9.

10. Khanolkar A, Vagero D, Koupil I. Social determinants of cardiac disease biomarkers: investigating a Swedish male cohort at ages 50 and 70 . Eur Jou Prev Cardio. 2011;19:523-33.

11. Gebreab SY, Roux-Diez AV, Hickson DA, Boykin S, Sims AM, Sarpong DF, Taylor HA, Wyatt SB. The contribution of stress to the social patterning of clinical and subclinical risk factors in African Americans: the Jackson heart study. Soc Sci Med. 2012;75:1697-707.

12. Hug C, Lodish HF. The role of the adipocyte hormone adiponectin in cardiovascular health. Curr Opin Phar. 2005;5:129-34.

13. Sonnenberg GE, Krakower GR, Kissebah AH. A novel pathway to the manifestation of metabolic syndrome. Obes Res. 2004;12:180-6.

14. Iwashima Y, Katsuya T, Ishikawa K, Ouchi N, Ohishi M, Sugimoto K, Fu Y, Motone M, Yamamoto K, Matsuo A, Ohashi K, Kihara S, Funahashi T, Rakugi $\mathrm{H}$, Matsuzawa Y, Ogihara T. Hypoadiponectinemia is an independent risk factor for hypertension. Hypertension. 2004;43:1318-23.

15. Hulver MW, Saleh O, MacDonald KG, Pories WJ, Barakect HA. Ethnic differences in adiponectin levels. Metabolism. 2004;53:1-3.

16. National Center for Health Statistics. Health, united states, 2011: with special feactures on socioeconomic status and health. US department of health and human services. Hyattsville: Centers for Disease Control and Prevention; 2012.

17. Buchan DS, Ollis S, Thomas NE, Simpson A, Young JD, Cooper SM, Malina RM, Cockcroft JR, Baker JS. Prevalence of traditional and novel markers of cardiovascular disease risk in Scottish adolescents: socioeconomic effects. App Physiol Nutr Metab. 2012;37:829-39.

18. Waisberg R, Paiker JE, Crowther NJ. Adipokine serum concentrations, anthropometric measurements and socio-economic status in two ethnic groups with different prevalence levels for cardiovascular disease and type 2 diabetes. Horm Metab Res. 2011;43:660-6.

19. Taylor HA. The Jackson heart study: an overview. Ethn Dis. 2005;15(4):1-3. suppl 6.

20. Carpenter MA, Crow R, Steffes M, Rock W, Heibraun J, Evans G, Skelton T, Jensen R, Sarpong D. Laboratory, reading center, and coordinating center data management methods in the Jackson heart study. Am J Med Sci. 2004;328:131-44.

21. Shand B, Elder P, Scott R, Frmapton C, Willis J. Biovariability of plasma and adiponectin. Clin Chem Lab Med. 2006;44:1264-8.

22. Mattehews DR, Hosker JP, Rudenski AS, Naylor BA, Treacher DF, Turner RC. Homeostatsis model assessment: insulin resistance and beta-cell function from fasting plasma glucose and insulin concentration in men. Diabetologia. 1985;28:412-9.

23. Bidulescu A, Liu J, Chen Z, Hickson DA, Musani SK, Samdarshi TE, Fox ER, Taylor HA, Gibbons GH. Associations of adiponectin and leptin with incident coronary heart disease and ischemic stroke in African Americans: the Jackson heart study. Fron Pub Health. 2013;16:1-7.

24. Duncan BB, Schmidt MI, Pankow JS, Bang H, Couper D, Ballentyne CM, Hoogeveen RC, Heiss G. Adiponectin and the development of type 2 diabetes: the atherosclerosis risk in communities study. Diabetes. 2004;53:24-2478.

25. SAS Institute Inc, Cary, North Carolina.

26. Cnop M, Havel PJ, Utzschneider KM, Carr DB, Sinha MK, Boyle EJ. Relationship of adiponectin to body fat distribution, insulin sensitivity and plasma lipoproteins: evidence for independent roles of age and sex. Diabetologia. 2013;43:459-69.

27. Friedman EM, Herd P. Income, education, and inflammation: differential associations in a national probability sample (the MIDUS study). Psycho Med. 2010;72:290-300.

28. Herd P, Goesling B, House JS. Socioeconomic position and health: the differential effects of education versus income on the onset versus progression of health problems. J Health Soc Behav. 2007:48:223-38.

29. Ross CE, Mirowsky J. Refining the association between education and health: the effects of quantity, credential, and selectivity. Demography. 1999;36:445-60. 
30. Lubbock LA, Goh A, Ali S, Ritchie J, Whooley MA. Relation of low socioeconomic status to $\mathrm{C}$-reactive protein in patients with coronary heart disease (from the heart and soul study). Am J Cardio. 2005;96:1506-11.

31. Waki H, Yamauchi T, Kamon J, Ito Y, Uchida S, Kita S, Hara K, Hada Y, Vasseur F, Froquel P, Kimura S, Nagai R, Kadowaki T. Impaired multimerization of human adiponectin mutants associated with diabetes. Molecular structure and multimer formation of adiponectin. J Biol Chem. 2003;278:40352-63.

32. Glintborg D, Frystyk J, Hojlund K, Anderson KK, Henriksen JE, Hermann AP, Hagen C, Flyvbjerg A, Anderson M. Total and high molecular weight (HMW) adiponectin levels and measures of glucose and lipid metalolism following pioglitazone treatment in a randomized placebo-controlled study in polycystic ovary syndrome. Clin Endocrinol. 2008;68:165-74.

Submit your next manuscript to BioMed Central and we will help you at every step:

- We accept pre-submission inquiries

- Our selector tool helps you to find the most relevant journal

- We provide round the clock customer support

- Convenient online submission

- Thorough peer review

- Inclusion in PubMed and all major indexing services

- Maximum visibility for your research

Submit your manuscript at www.biomedcentral.com/submit
Biomed Central 